\title{
Alcohol consumption and distinct molecular pathways to colorectal cancer
}

\author{
Brenda W. C. Bongaerts ${ }^{1 *}$, Anton F. P. M. de Goeij ${ }^{2}$, Stefan de Vogel $^{3}$, Piet A. van den Brandt ${ }^{1}$, \\ R. Alexandra Goldbohm ${ }^{4}$ and Matty P. Weijenberg ${ }^{1}$ \\ ${ }^{1}$ Nutrition and Toxicology Research Institute Maastricht (NUTRIM), Department of Epidemiology, University Maastricht, \\ 6200 MD Maastricht, The Netherlands \\ ${ }^{2}$ Research Institute Growth and Development (GROW), Department of Pathology, University Maastricht, \\ 6200 MD Maastricht, The Netherlands \\ ${ }^{3}$ Research Institute Growth and Development (GROW), Departments of Epidemiology and Pathology, \\ University Maastricht, 6200 MD Maastricht, The Netherlands \\ ${ }^{4}$ Department of Food \& Chemical Risk Analysis, TNO Quality of Life, 3700 AJ Zeist, The Netherlands
}

(Received 30 June 2006 - Revised 11 August 2006 - Accepted 17 October 2006)

\begin{abstract}
High alcohol consumption is related to colorectal cancer (CRC). Our objective was to study associations between alcohol consumption and risk of CRC according to characteristics of aetiological pathways: the chromosomal instability (CIN) and the microsatellite instability (MIN) pathway. We classified $\mathrm{CIN}^{+}$tumours (tumours with either a truncating APC mutation, an activating $K$-ras mutation or overexpression of p53), MIN ${ }^{+}$ tumours (tumours lacking hMLH1 expression) and $\mathrm{CIN}^{-} / \mathrm{MIN}^{-}$tumours (tumours without these defects). In the Netherlands Cohort Study on diet and cancer, 120852 men and women, aged 55-69 years, completed a questionnaire on risk factors for cancer at baseline (1986). Casecohort analyses were conducted using $573 \mathrm{CRC}$ cases with complete data after $7 \cdot 3$ years of follow-up, excluding the first $2 \cdot 3$ years. Adjusted incidence rate ratios (RR) and $95 \%$ confidence intervals (CI) were estimated. Compared with abstaining, alcohol consumption of $\geq 30 \mathrm{~g} / \mathrm{d}$ was positively associated with the risk of CRC irrespective of genetic or molecular aberrations present, although statistical significance was not reached (RR 1.35 (95\% CI 0.9-2.0) for the $\mathrm{CIN}^{+}$tumours, RR 1.59 (95\% CI 0.4-5.8) for the $\mathrm{MIN}^{+}$tumours and RR 1.15 (95\% CI $\left.0.5-2 \cdot 7\right)$ for the $\mathrm{CIN}^{-} / \mathrm{MIN}^{-}$tumours). Beer, wine and liquor consumption were, independent of their alcoholic content, not consistently associated with the risk of CRC within the defined subgroups. In conclusion, our results indicate that a daily alcohol consumption of $\geq 30 \mathrm{~g}$ is associated with an increase in risk of CRC, independent of the presence or absence of the studied characteristics of different aetiological pathways.
\end{abstract}

Alcohol: Colorectal cancer: Genetics: Cohort study: The Netherlands

Colorectal cancer (CRC) is characterised by multiple chromosomal abnormalities. It is one of the best studied models representing the multistep nature of tumorigenesis. Sporadic CRC may develop through at least two independent pathways, i.e. the chromosomal instability (CIN) and the microsatellite instability (MIN) pathways. The CIN pathway is characterised by aneuploidy/polyploidy and mutations in $A P C, K$-ras, p53 and DCC genes, and occasionally in SMAD2 and SMAD4 genes. The MIN pathway, on the other hand, is characterised by alterations in small stretches of short repetitive DNA sequences (microsatellites), and deficiency in DNA mismatch repair (MMR) which is often caused by promoter methylation of the MMR gene hMLH1 (Rashid et al. 1999; Arnold et al. 2004). Colorectal carcinomas that evolve through the CIN or MIN pathways differ in several pathological features such as tumour sublocalisation, tumour differentiation and patient survival (Salahshor et al. 1999; Samowitz et al. 2001; Giaretti et al. 2004; Lüchtenborg et al. 2005). This indicates that various environmental risk factors, such as dietary habits and lifestyle factors, may play a different role in the aetiology of CIN and MIN colorectal tumours.
The association between alcohol consumption and CRC has long been debated. Although alcohol itself is not carcinogenic, alcohol's first metabolite, acetaldehyde, is emerging as an important malefactor, being able to form stable DNA adducts, trigger mutations in tumour suppressors and oncogenes, and interfere with DNA repair (Poschl et al. 2004).

Several epidemiological studies have investigated associations between alcohol consumption and single genetic events involved in CRC, such as mutations in $A P C$ and $K$-ras genes, MIN and overexpression of p53 (Fredrikson et al. 1996; Slattery et al. 2000; Voskuil et al. 2000; Samowitz et al. 2001; Diergaarde et al. 2003a,b; Terry et al. 2003). Although these studies focused merely on a single gene and their results are not consistent, all positive associations that were found linked alcohol consumption to colorectal carcinomas harbouring the mutated version of the studied gene, but not the wild-type version. What needs further elucidation are the aetiological pathway(s) by which alcohol consumption may contribute to colorectal tumorigenesis.

\footnotetext{
Abbreviations: CI, confidence interval; CIN, chromosome instability; CRC, colorectal cancer; MIN, microsatellite instability; RR, rate ratio. * Corresponding author: Dr Brenda W. C. Bongaerts, fax: + 3143 3884128, email Brenda.Bongaerts@epid.unimaas.nl
} 
Our aim was to study the associations between alcohol consumption and the risk of CRC in subgroups of tumours, according to their genetic and molecular aberrations. We defined $\mathrm{CIN}^{+}$tumours as colorectal tumours with either a truncating $A P C$ mutation, an activating $K$-ras mutation or overexpression of $\mathrm{p} 53$, since these genes can be considered as key genes of the CIN pathway. MIN ${ }^{+}$tumours were defined according to a key feature of the MIN pathway, i.e. lack of hMLH1 expression. A third group of colorectal tumours was identified as $\mathrm{CIN}^{-} / \mathrm{MIN}^{-}$, i.e. tumours without the genetic and molecular aberrations characteristic for the $\mathrm{CIN}^{+}$and $\mathrm{MIN}^{+}$tumours.

The current study was conducted within the ongoing Netherlands Cohort Study on diet and cancer, and is the first to study alcohol consumption and subgroups of colorectal tumours, based on independent aetiological pathways of disease.

\section{Materials and methods}

\section{Study population}

In September 1986, the Netherlands Cohort Study on diet and cancer was initiated (van den Brandt et al. 1990a). Briefly, 120852 men and women, aged 55-69 years and originating from 204 municipal population registries throughout the country completed an extensive self-administered questionnaire on daily dietary habits, lifestyle and other risk factors for cancer. Newly diagnosed cancer cases were identified through annual record linkage to the Netherlands Cancer Registry and to PALGA, a nationwide database of histoand cytopathology reports (van den Brandt et al. 1990b).

The present analyses were carried out over a 7.3-year period of follow-up, excluding the first 2.3 years. Hence, 925 histologically confirmed CRC cases were identified between January 1989 and January 1994, of whom 815 could be linked to a PALGA report of the lesion.

Data processing and analysis were done according to the case-cohort approach: cases were identified in the entire cohort, while a random sample of the cohort (subcohort) was used to estimate person-years at risk accumulating in the cohort. A subcohort of 5000 men and women was followed-up biennially to assess information on vital status and migration. Prevalent cancer cases, other than non-melanoma skin cancer, were excluded from the subcohort, as well as subjects who were deceased or were diagnosed with cancer during the first 2.3 years of follow-up. This left 4673 subcohort members for analyses.

\section{Assessment of exposure}

Information on alcohol consumption was obtained from the baseline questionnaire, which comprised a 150-item semiquantitative FFQ. This questionnaire has been validated against a $9 \mathrm{~d}$ diet record (Goldbohm et al. 1994). The Spearman correlation coefficient between mean daily alcohol consumption assessed by the questionnaire and estimated from the $9 \mathrm{~d}$ diet record was 0.89 for all subjects and 0.85 for users of alcoholic beverages. The absolute amount of alcohol consumption reported in the questionnaire by users of alcoholic beverages was, on average, $86 \%$ of that reported in the $9 \mathrm{~d}$ diet record.

\section{Tissue samples and molecular analyses}

Of the 815 eligible CRC cases, 771 formalin-fixed, paraffinembedded tissue blocks could be retrieved from Dutch pathology archives. Samples that did not contain carcinoma tissue were excluded. As previously described, tissue samples of 734 CRC cases were available for molecular analyses of K-ras (Brink et al. 2003) and APC (Lüchtenborg et al. 2004) genes, and immunohistochemical staining of hMLH1 (Lüchtenborg et al. 2005) and p53.

Immunohistochemical staining for p53 was performed on archival adenocarcinoma specimens of all 734 CRC cases according to the avidin-biotin-peroxidase complex method, using the DO-7 mouse monoclonal antibody (DAKO A/S, Denmark). Immunostained slides and negative controls were evaluated semi-quantitatively and independently by two observers without knowledge of clinical parameters. We defined cases positive for overexpression of p53 if $20 \%$ or more of the tumour cell nuclei showed positive staining with the antibody.

\section{Statistical analysis}

All subjects with complete information on alcohol consumption and confounding variables derived from the baseline questionnaire, and CRC cases for whom information on $A P C, K$-ras, p53 and hMLH1 status was also known, were included in the statistical analysis (4076 subcohort members and 573 CRC cases).

Incidence risk ratios (RR) and corresponding $95 \%$ confidence intervals (CI) were estimated using Cox proportional hazards models. Total alcohol consumption was divided into three categories: $0,<30.0$ and $\geq 30.0 \mathrm{~g} / \mathrm{d}$, in line with the results of a recent pooled analysis that suggested a threshold in alcohol consumption above which the risk of CRC increases (Cho et al. 2004). Consumption of beer, wine and liquor were considered dichotomously. Analyses were adjusted for age at baseline (years), sex, BMI $\left(\mathrm{kg} / \mathrm{m}^{2}\right)$, family history of CRC (yes $v$. no), daily intakes of total energy $(\mathrm{kJ} / \mathrm{d})$, linoleic acid (g/d) and calcium (mg/d), and smoking (never, ex, current smoker). The analyses of the alcoholic beverages were additionally adjusted for total alcohol intake (categorised as $0,<30.0$ and $\geq 30.0 \mathrm{~g} / \mathrm{d}$ ), to evaluate the role of the specific beverage independently of its alcoholic content. The analyses were performed using the STATA statistical software package (version 9.1).

\section{Results}

Table 1 shows drinking habits and baseline characteristics of the subcohort and CRC cases classified according to the studied genetic and molecular defects. Of the $471 \mathrm{CIN}^{+}$colorectal tumours, $38(8 \%)$ tumours only had a truncating $A P C$ mutation, $46(9 \%)$ only had an activating $K$-ras mutation and $168(36 \%)$ tumours only showed overexpression of p53. In addition, $174(37 \%)$ of the $\mathrm{CIN}^{+}$tumours had two of the described aberrations and $45(10 \%)$ had all three aberrations. Compared with the $\mathrm{CIN}^{+}$cases, the $\mathrm{MIN}^{+}$cases comprised significantly more female cases, had fewer liquor consumers and a lower daily intake of total energy. No differences in drinking habits or baseline characteristics between the 
Table 1. Drinking habits and baseline characteristics (mean and SD) of the subcohort members and subgroups of CRC characterized by specific genetic and molecular aberrations, the Netherlands Cohort Study (1986-1993)

(Mean values and standard deviations)

\begin{tabular}{|c|c|c|c|c|c|c|c|c|}
\hline & \multicolumn{2}{|c|}{ Subcohort } & \multicolumn{2}{|c|}{$\mathrm{CIN}^{+}$tumours* } & \multicolumn{2}{|c|}{$\mathrm{MIN}^{+}$tumours $\dagger$} & \multicolumn{2}{|c|}{$\mathrm{CIN}^{-} / \mathrm{MIN}^{-}$tumours $\ddagger$} \\
\hline & Mean & SD & Mean & SD & Mean & SD & Mean & SD \\
\hline$n$ & 4076 & & 471 & & 32 & & 87 & \\
\hline Age (years) & $61 \cdot 3$ & 4.2 & 62.6 & 41 & 63.5 & 4.4 & 63.4 & $3 \cdot 7$ \\
\hline Sex (\% male) & 50 & & 59 & & 41 & & 52 & \\
\hline \multicolumn{9}{|l|}{ Alcohol consumption } \\
\hline Total alcohol (g/d) & $10 \cdot 4$ & 14.4 & $11 \cdot 8$ & $15 \cdot 3$ & $10 \cdot 9$ & $14 \cdot 8$ & $10 \cdot 8$ & $13 \cdot 0$ \\
\hline Beer (glasses/week) & $1 \cdot 7$ & $5 \cdot 3$ & $1 \cdot 8$ & 4.7 & $2 \cdot 0$ & $7 \cdot 3$ & $1 \cdot 8$ & 5.9 \\
\hline Wine (glasses/week & $2 \cdot 6$ & $5 \cdot 0$ & $2 \cdot 8$ & $5 \cdot 5$ & 3.9 & $7 \cdot 4$ & 2.5 & 4.8 \\
\hline Liquor (glasses/week) & 2.5 & $5 \cdot 2$ & 3.0 & $5 \cdot 6$ & 1.5 & 3.4 & $2 \cdot 9$ & $5 \cdot 7$ \\
\hline \multicolumn{9}{|l|}{ Molecular characteristics§ } \\
\hline Truncating $A P C$ mutation & & & 201 & & 0 & & 0 & \\
\hline Activating $K$-ras mutation & & & 194 & & 0 & & 0 & \\
\hline Overexpression of p53 & & & 340 & & 0 & & 0 & \\
\hline Lack of hMLH1 expression & & & 0 & & 32 & & 0 & \\
\hline \multicolumn{9}{|l|}{ Other lifestyle factors } \\
\hline Family history of CRC (\% yes) & 6 & & 10 & & 13 & & 15 & \\
\hline $\mathrm{BMI}\left(\mathrm{kg} / \mathrm{m}^{2}\right)$ & $25 \cdot 0$ & $3 \cdot 1$ & 25.5 & 3.0 & 25.5 & 3.4 & 25.4 & 3.7 \\
\hline Energy intake (kJ/d) & 8074 & 2160 & 8162 & 2060 & 7294 & 1713 & 7990 & 2041 \\
\hline Linoleic acid intake $(\mathrm{g} / \mathrm{d}) \boldsymbol{q}$ & $14 \cdot 4$ & 7.5 & $15 \cdot 1$ & 7.7 & $14 \cdot 2$ & 5.7 & 14.8 & 8.1 \\
\hline Calcium intake $(\mathrm{mg} / \mathrm{d}) \|$ & 925 & 282 & 932 & 270 & 888 & 219 & 934 & 271 \\
\hline \multicolumn{9}{|l|}{ Smoking (\%) } \\
\hline Never smoker & 36 & & 32 & & 28 & & 33 & \\
\hline Ex-smoker & 36 & & 46 & & 41 & & 50 & \\
\hline Current smoker & 28 & & 22 & & 31 & & 17 & \\
\hline
\end{tabular}

CRC, colorectal cancer; CIN, chromosome instability; MIN, microsatellite instability.

* Defined as colorectal tumours presenting either a truncating $A P C$ mutation, an activating $K$-ras mutation or overexpression of p53.

tDefined as colorectal tumours presenting lack of hMLH1 expression only.

$\ddagger$ Defined as colorectal tumours presenting no truncating APC mutation, nor an activating $K$-ras mutation, overexpression of p53 or lack of hMLH1 expression.

$\S \mathrm{Of}$ the $\mathrm{CIN}^{+}$tumours, thirty-eight harboured a truncating APC mutation only, forty-six an activating K-ras mutation only and 168 only showed overexpression of p53. In addition, $174 \mathrm{CIN}^{+}$tumours harboured two of these aberrations and forty-five harboured all three aberrations.

I Adjusted for total energy intake.

|| Adjusted for energy intake from dairy products.

$\mathrm{CIN}^{-} / \mathrm{MIN}^{-}$cases and both $\mathrm{CIN}^{+}$and $\mathrm{MIN}^{+}$cases were observed.

Table 2 reports the RR and $95 \%$ CI for total alcohol consumption and different types of alcoholic beverages, and the risk of CRC according to the presence or absence of specific genetic and molecular aberrations. Compared with abstaining, consumption levels of total alcohol $\geq 30 \mathrm{~g} / \mathrm{d}$ were associated with an increased risk of CRC irrespective of genetic or molecular aberrations present, although statistical significance was not reached (RR: 1.35 (95\% CI: 0.9-2.0) for the $\mathrm{CIN}^{+}$ tumours, RR: 1.59 (95\% CI: $0.4-5 \cdot 8)$ for the $\mathrm{MIN}^{+}$tumours and RR: $1.15(95 \% \mathrm{CI}: 0.5-2 \cdot 7)$ for the $\mathrm{CIN}^{-} / \mathrm{MIN}^{-}$ tumours). Beer, wine and liquor consumption, after adjustment for total alcohol intake, showed no clear relationship with $\mathrm{CIN}^{+}, \mathrm{MIN}^{+}$and $\mathrm{CIN}^{-} / \mathrm{MIN}^{-}$tumours.

\section{Discussion}

We investigated associations between alcohol consumption and the risk of CRC by involvement of the CIN and MIN aetiological pathways in a large prospective study. In this study, we defined $\mathrm{CIN}^{+}$tumours as tumours harbouring either a truncating $A P C$ mutation, an activating $K$-ras mutation or overexpression of $\mathrm{p} 53$, and the $\mathrm{MIN}^{+}$tumours as tumours lacking expression of hMLH1. A third group of colorectal tumours did not harbour any of these defects and was defined as $\mathrm{CIN}^{-} / \mathrm{MIN}^{-}$. Our results indicate that, compared with abstaining, alcohol consumption levels $\geq 30 \mathrm{~g} / \mathrm{d}$ were associated with an increased risk of CRC, which was observed in all three subgroups, although statistical significance was not reached. Within all three subgroups, no associations were observed between different alcoholic beverages adjusted for total alcohol consumption, and the risk of CRC.

In line with the present results, positive associations between alcohol consumption and CRC with single genetic or molecular aberrations have been reported for colorectal tumours that showed overexpression of p53 and colon tumours with MIN (Fredrikson et al. 1996; Samowitz et al. 2001; Diergaarde et al. 2003a; Terry et al. 2003), but not for colon tumours harbouring mutations in the $A P C$ and $K$-ras genes (Slattery et al. 2000; Diergaarde et al. 2003b). We performed additional analyses for alcohol consumption and the risk of CRC in which we considered each genetic or molecular aberration independently of any other simultaneously present genetic or molecular aberration(s), but the results of these analyses did not alter our present conclusions.

The pathological effects of alcohol consumption on the colorectal tract have been extensively investigated but still remain largely unclear. Evidence exists for the involvement of acetaldehyde (Taylor \& Rehm, 2005), but also other mechanisms have been linked to $\mathrm{CRC}$, e.g. the induction of reactive oxygen species through the induction of cytochrome P-450 2E (Badger et al. 2003; Seitz et al. 2005; Boffetta \& Hashibe, 
Table 2. Incidence rate ratios for subgroups of colorectal cancer characterized by specific genetic and molecular aberrations, according to drinking habits, adjusted for confounders*, the Netherlands Cohort Study (1986-1993)

\begin{tabular}{|c|c|c|c|c|c|c|c|c|c|c|}
\hline \multirow[b]{2}{*}{ Drinking habits } & \multirow{2}{*}{$\begin{array}{l}\text { Person-years } \\
\text { in subcohort }\end{array}$} & \multicolumn{3}{|c|}{$\mathrm{CIN}^{+}$tumours $†$} & \multicolumn{3}{|c|}{$\mathrm{MIN}^{+}$tumoursł } & \multicolumn{3}{|c|}{$\mathrm{CIN}^{-} / \mathrm{MIN}^{-}$tumours $\S$} \\
\hline & & No. of cases & $\mathrm{RR}$ & $95 \% \mathrm{Cl}$ & No. of cases & $\mathrm{RR}$ & $95 \% \mathrm{Cl}$ & No. of cases & $\mathrm{RR}$ & $95 \% \mathrm{Cl}$ \\
\hline \multicolumn{11}{|l|}{ Total alcohol (g/d) } \\
\hline No alcohol & 6762 & 103 & 1.00 & & 9 & 1.00 & & 22 & 1.00 & \\
\hline$<30.0$ & 19656 & 308 & 0.97 & $0.8,1 \cdot 2$ & 19 & 0.81 & $0.4,1.9$ & 56 & 0.87 & $0.5,1.5$ \\
\hline$\geq 30 \cdot 0$ & 2624 & 60 & 1.35 & $0.9,2 \cdot 0$ & 4 & 1.59 & $0 \cdot 4,5 \cdot 8$ & 9 & $1 \cdot 15$ & $0 \cdot 5,2 \cdot 7$ \\
\hline \multicolumn{11}{|c|}{ Beer (glasses/week) } \\
\hline No beer & 19320 & 307 & 1.00 & & 25 & 1.00 & & 61 & 1.00 & \\
\hline Beer drinker & 9722 & 164 & 0.82 & $0 \cdot 6,1 \cdot 1$ & 7 & 0.60 & $0 \cdot 2,1 \cdot 7$ & 26 & 0.85 & $0.5,1.5$ \\
\hline \multicolumn{11}{|c|}{ Wine (glasses/week) } \\
\hline No wine & 13601 & 224 & 1.00 & & 16 & 1.00 & & 43 & 1.00 & \\
\hline Wine drinker & 15441 & 247 & 0.97 & $0 \cdot 8,1 \cdot 2$ & 16 & 0.89 & $0 \cdot 3,2 \cdot 3$ & 44 & 0.83 & $0.5,1.5$ \\
\hline \multicolumn{11}{|c|}{ Liquor (glasses/week) } \\
\hline No liquor & 14883 & 211 & 1.00 & & 19 & 1.00 & & 43 & 1.00 & \\
\hline Liquor drinker & 14159 & 260 & $1 \cdot 15$ & $0.9,1.5$ & 13 & 0.73 & $0.3,1.9$ & 44 & $1 \cdot 13$ & $0.7,1.9$ \\
\hline
\end{tabular}

$\mathrm{CIN}$, chromosome instability; MIN, microsatellite instability; RR, rate ratio; $\mathrm{Cl}$, confidence interval.

${ }^{*}$ Adjusted for age (years), sex, BMI $\left(\mathrm{kg} / \mathrm{m}^{2}\right)$, family history of colorectal cancer (yes/no), daily energy intake (kJ/d), daily linoleic acid intake (g/d), daily calcium intake (mg/d) and smoking (never, ex, current).

tDefined as colorectal tumours presenting either a truncating $A P C$ mutation, an activating $K$-ras mutation or overexpression of $\mathrm{p} 53$.

$\ddagger$ Defined as colorectal tumours presenting lack of hMLH1 expression only.

$\S$ Defined as colorectal tumours presenting no truncating APC mutation, nor an activating $K$-ras mutation, overexpression of p53 or lack of hMLH1 expression

I Additionally adjusted for categories of total alcohol consumption $(0,<30 \cdot 0, \geq 30.0 \mathrm{~g} / \mathrm{d})$.

2006). Other molecular changes seen in CRC involve alterations in DNA methylation, e.g. induction of expression of oncogenes and silencing of tumour suppressor genes. Choi et al. (1999) demonstrated that chronic alcohol consumption causes genomic DNA hypomethyation in rats, whereas no effect was seen on the methylation status of the tumour suppressor gene p53. Next to effects at the genomic level, alcohol may also affect the colorectal mucosa. As shown in experimental studies, decreasing cell numbers in the functional compartment of the colonic crypt through acetaldehyde, trigger compensatory hyper-regeneration with increased crypt cell production rates and extension of the proliferative compartment towards the lumen of the crypt (Seitz et al. 1990; Simanowski et al. 2001). Mucosal hyperregeneration, regardless of the underlying cause, is strongly associated with CRC risk. Many of the above-described processes have been observed in heavy or chronic alcohol consumers. The amount of damage related to alcohol tends to follow a dose-response relationship and, as such, (very) high levels of daily alcohol intake may be needed for genetic mutations to occur. Moderate consumption levels, as in our study population, might thus not be able to increase CRC risk through causing specific genetic or molecular aberrations. In addition, besides adverse effects of alcohol consumption, the entire nutritional status in heavy drinkers may be impaired due to malnutrition and intestinal absorption, increasing the cancer risk even more.

The strengths of our study include a population-based and prospective design. In addition, the high completeness of follow-up of cancer incidence and subcohort members precluded minimal recall and selection biases. Although the CIN and MIN pathways also involve aberrations other than the ones that were included in the current study, $A P C, K$-ras and p53 are key genes of the CIN pathway, as $h M L H 1$ is a key gene of the MIN pathway. Our study is currently the first prospective study that investigated the association between alcohol consumption and distinct CRC subgroups. Nevertheless, it should be noted that the numbers of CRC cases in certain subgroups are small and results should be interpreted with caution.

In conclusion, our results indicate that a daily alcohol consumption of $\geq 30 \mathrm{~g}$ is positively associated with the risk of CRC. This increase in risk was observed independent of the presence or absence of the genetic and molecular aberrations we studied to distinguish between aetiological pathways.

\section{Acknowledgements}

We are indebted to the participants of this study and further thank the regional cancer registries (IKA, IKL, IKMN, IKN, IKO, IKR, IKST, IKW, IKZ and VIKC), and the Netherlands nationwide registry of pathology (PALGA). We also thank all the Dutch pathology laboratories for their cooperation in providing the tissue blocks, Dr M. Brink for the collection of tissue samples, Dr A. de Bruïne for expert pathological advice, Dr M. Brink, Dr M. Lüchtenborg, P. Wark, G. Roemen, K. Wouters and Dr M van Engeland for molecular analyses, Dr L. Schouten, S. van de Crommert, H. Brants, J. Nelissen, C. de Zwart, M. Moll, W. van Dijk, M. Jansen and A. Pisters for data management, and H. van Montfort, T. van Moergastel, L. van den Bosch and R. Schmeitz for programming assistance. Finally, we thank Dr A. Volovics and Dr A. Kester for statistical advice. Financial support for collection of tumour material and mutation analyses was provided by a grant from the Dutch Cancer Society and financial support for the current study is provided by a grant from the European Research Advisory Board (ERAB).

\section{References}

Arnold CN, Goel A, Compton C, et al. (2004) Evaluation of microsatellite instability, hMLH1 expression and hMLH1 promoter hypermethylation in defining the MSI phenotype of colorectal cancer. Cancer Biol Ther 3, 73-78. 
Badger TM, Ronis MJ, Seitz HK, Albano E, Ingelman-Sundberg M \& Lieber CS (2003) Alcohol metabolism: role in toxicity and carcinogenesis. Alcohol Clin Exp Res 27, 336-347.

Boffetta P \& Hashibe M (2006) Alcohol and cancer. Lancet Oncol 7, $149-156$.

Brink M, de Goeij AF, Weijenberg MP, Roemen GM, Lentjes MH, Pachen MM, Smits KM, de Bruine AP, Goldbohm RA \& van den Brandt PA (2003) K-ras oncogene mutations in sporadic colorectal cancer in The Netherlands Cohort Study. Carcinogenesis 24, 703-710.

Cho E, Smith-Warner SA, Ritz J, et al. (2004) Alcohol intake and colorectal cancer: a pooled analysis of 8 cohort studies. Ann Intern Med 140, 603-613.

Choi SW, Stickel F, Baik HW, Kim YI, Seitz HK \& Mason JB (1999) Chronic alcohol consumption induces genomic but not $\mathrm{p} 53$-specific DNA hypomethylation in rat colon. J Nutr 129, 1945-1950.

Diergaarde B, Braam H, van Muijen GN, Ligtenberg MJ, Kok FJ \& Kampman E (2003a) Dietary factors and microsatellite instability in sporadic colon carcinomas. Cancer Epidemiol Biomarkers Prev 12, 1130-1136.

Diergaarde B, van Geloof WL, van Muijen GN, Kok FJ \& Kampman E (2003) Dietary factors and the occurrence of truncating APC mutations in sporadic colon carcinomas: a Dutch populationbased study. Carcinogenesis 24, 283-290.

Fredrikson M, Axelson O, Sun XF, Arbman G, Nilsson E, Nordenskjold B, Sjodahl R \& Soderkvist P (1996) A pilot study on risk factors and p53 gene expression in colorectal cancer. Br J Cancer 73, 1428-1430.

Giaretti W, Venesio T, Prevosto C, Lombardo F, Ceccarelli J, Molinu S \& Risio M (2004) Chromosomal instability and APC gene mutations in human sporadic colorectal adenomas. J Pathol 204, 193-199.

Goldbohm RA, van den Brandt PA, Brants HA, van't Veer P, Al M, Sturmans F \& Hermus RJ (1994) Validation of a dietary questionnaire used in a large-scale prospective cohort study on diet and cancer. Eur J Clin Nutr 48, 253-265.

Lüchtenborg M, Weijenberg MP, Roemen GMJM, de Bruïne AP, van den Brandt PA, Lentjes MHFM, Brink M, van Engeland M, Goldbohm RA \& de Goeij AFPM (2004) APC mutations in sporadic colorectal carcinomas from The Netherlands Cohort Study. Carcinogenesis 25, 1219-1226.

Lüchtenborg M, Weijenberg MP, Wark PA, Saritas AM, Roemen GMJM, van Muijen GNP, de Bruine AP, van den Brandt PA \& de Goeij AFPM (2005) Mutations in APC, CTNNBI and K-ras genes and expression of hMLHI in sporadic colorectal carcinomas from the Netherlands Cohort Study. BMC Cancer 5, 160.
Poschl G, Stickel F, Wang XD \& Seitz HK (2004) Alcohol and cancer: genetic and nutritional aspects. Proc Nutr Soc 63, 65-71.

Rashid A, Zahurak M, Goodman SN \& Hamilton SR (1999) Genetic epidemiology of mutated K-ras proto-oncogene, altered suppressor genes, and microsatellite instability in colorectal adenomas. Gut $\mathbf{4 4}$, 826-833.

Salahshor S, Kressner U, Påhlman L, Glimelius B, Lindmark G \& Lindblom A (1999) Colorectal cancer with and without microsatellite instability involves different genes. Genes Chromosomes Cancer 26, 247-252.

Samowitz WS, Holden JA, Curtin K, et al. (2001) Inverse relationship between microsatellite instability and K-ras and $p 53$ gene alterations in colon cancer. Am J Pathol 158, 1517-1524.

Seitz HK, Maurer B \& Stickel F (2005) Alcohol consumption and cancer of the gastrointestinal tract. Dig Dis 23, 297-303.

Seitz HK, Simanowski UA, Garzon FT, Rideout JM, Peters TJ, Koch A, Berger MR, Einecke H \& Maiwald M (1990) Possible role of acetaldehyde in ethanol-related rectal cocarcinogenesis in the rat. Gastroenterology 98, 406-413.

Simanowski UA, Homann N, Knuhl M, Arce L, Waldherr R, Conradt C, Bosch FX \& Seitz HK (2001) Increased rectal cell proliferation following alcohol abuse. Gut 49, 418-422.

Slattery ML, Curtin K, Anderson K, Ma KN, Edwards S, Leppert M, Potter J, Schaffer D \& Samowitz WS (2000) Associations between dietary intake and Ki-ras mutations in colon tumors: a populationbased study. Cancer Res 60, 6935-6941.

Taylor B \& Rehm J (2005) Moderate alcohol consumption and diseases of the gastrointestinal system: a review of pathophysiological processes. Dig Dis 23, 177-180.

Terry MB, Neugut AI, Mansukhani M, Waye J, Harpaz N \& Hibshoosh H (2003) Tobacco, alcohol, and p53 overexpression in early colorectal neoplasia. BMC Cancer 3, 29.

van den Brandt PA, Goldbohm RA, van't Veer P, Volovics A, Hermus RJ \& Sturmans F (1990a) A large-scale prospective cohort study on diet and cancer in The Netherlands. J Clin Epidemiol 43, 285-295.

van den Brandt PA, Schouten LJ, Goldbohm RA, Dorant E \& Hunen PM (1990b) Development of a record linkage protocol for use in the Dutch Cancer Registry for Epidemiological Research. Int $J$ Epidemiol 19, 553-558.

Voskuil DW, Kampman E, Van Geloof W, Grubben M, Kok F, Van Muijen G, Nagengast F, Vasen H \& van't Veer P (2000) No major difference in K-ras and p53 abnormalities in sporadic and hereditary nonpolyposis colorectal adenomas. Dig Dis Sci 45, 2187-2194. 